\title{
Effects of backpack loads and positions on the variability of gait spatiotemporal parameters in young adults
}

\author{
Georgia Cristina Lehnen ${ }^{*}$, Rina Marcia Magnani ${ }^{1}$, Gustavo Souto de Sá e Souza ${ }^{1}$, \\ Fábio Barbosa Rodrigues ${ }^{1}$, Adriano de Oliveira Andrade ${ }^{2}$, Marcus Fraga Vieira ${ }^{1}$ \\ ${ }^{1}$ Bioengineering and Biomechanics Laboratory, Federal University of Goiás, Goiânia, GO, Brazil. \\ ${ }^{2}$ Centre for Innovation and Technology Assessment in Health, Federal University of Uberlândia, Uberlândia, MG, Brazil.
}

\begin{abstract}
Introduction: People carry backpacks of different weight in different positions every day. The effects of backpack wearing under different loads and positions were assessed according to the gait's spatiotemporal parameters and their variability in young adults. Methods: Twenty-one subjects performed trials of $4 \mathrm{~min}$ in the conditions: control condition with no backpack; bilateral back load consisting of $10 \%$ body weight (BW); bilateral back load of $20 \%$ BW (B20); unilateral load of 10\% BW; unilateral load with $20 \%$ BW (U20); bilateral frontal load with $10 \%$ BW; bilateral frontal load with 20\% BW. Results: Step length (SL) and step frequency (SF) show that frontal conditions differed from others as seen in B20. Gait cycle phases showed an increase in the B20 condition for double stance phase and stance phase, swing phase presented reduction in the B20 condition. There were significant main effects in position for SL, SF, and walk ratio, in load only for stride width. The highest variability of spatiotemporal parameters occurred in the U20 condition. All load conditions with $20 \%$ BW showed a greater variability when compared to the $10 \%$ BW counterpart. Conclusion: We concluded that young adults can cope with up to a $15 \% \mathrm{BW}$ load under a bilateral back position, but in the frontal position not even a 10\% BW load was proven to be a safe limit. 20\% BW loads should be avoided in any position. These recommendations may assure increased gait stability, decreased trunk forward lean and decreased muscle activation and fatigue reducing back pain occurrence.
\end{abstract}

Keywords Human gait, Stance phase, Swing phase, Walk ratio, Stride width, Gait variability.

\section{Introduction}

People use backpacks on a daily basis, typically carried over their shoulders to leave the upper limbs free for other activities and to make it more comfortable when carrying loads (Abaraogu et al., 2016; Heuscher et al., 2010). Overly heavy backpacks and inadequate carrying methods may distribute the weight inappropriately causing back pain (Heuscher et al., 2010; Sheir-Neiss et al., 2003),

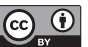

This is an Open Access article distributed under the terms of the Creative Commons Attribution License, which permits unrestricted use, distribution, and reproduction in any medium, provided the original work is properly cited.

How to cite this article: Lehnen GC, Magnani RM, Souza GSS, Rodrigues FB, Andrade AO, Vieira MF. Effects of backpack loads and positions on the variability of gait spatiotemporal parameters in young adults. Res Biomed Eng. 2017; 33(4):277-284 DOI: $10.1590 / 2446-4740.03517$.

*Corresponding author: Bioengineering and Biomechanics Laboratory, Federal University of Goiás, Av. Esperança, s/n, Campus Samambaia, CEP 74690-900, Goiânia, GO, Brazil. Email: georgialehnen@hotmail.com

Received: 29 June 2017 / Accepted: 20 August 2017 muscle fatigue, and increased tension in different parts of the body, which may cause undesired posture and spinal deformity (Abaraogu et al., 2016; Berceanu et al., 2016; Brackley et al., 2009; Hong et al., 2008).

From a biomechanical perspective, improper posture causes alterations in gait pattern. However, as people habitually carry backpacks, they tend to neglect potential problems and adverse effects that could be associated with the weight and position of backpacks (Abaraogu et al., 2016). Thus, there are concerns regarding backpack use, particularly in young people, since backpack weight can be considered heavy in terms of body weight (BW) percentage, reaching values as high as 20\% (Pau et al., 2011; Sheir-Neiss et al., 2003).

Several studies have reported alteration in the kinematic and kinetic aspects of gait associated with backpack use, as noted by the changes in spatiotemporal parameters. Those changes included reduced speed, cadence, step length, single support phase, and increased double support phase and stride duration (Birrell and Haslam, 2009; Chow et al., 2005; Qu and Yeo, 2011; Singh and Koh, 2009; Wang et al., 2001). There are reports of 
changes at the ankle, hip, trunk and in pelvis angles (Birrell and Haslam, 2009; Dames and Smith, 2015; Devroey et al., 2007; LaFiandra et al., 2003), along with increased ground reaction forces (Berceanu et al., 2016; Chow et al., 2005) with increasing load.

The gait spatiotemporal parameters, especially phases' periods, are important to the diagnosis of both healthy and pathological gaits, and in tracking clinical outcomes (Hebenstreit et al., 2015). However, to our knowledge, the majority of studies have investigated the effect of backpack on the gait spatiotemporal parameters among young adults, in the military context (Attwells et al., 2006; Birrell and Haslam, 2009; Knapik et al., 2004; Majumdar et al., 2010; Springer et al., 2016; Yoo, 2014) and focusing on children and teenagers (Brackley et al., 2009; Chow et al., 2005; Hong et al., 2008; Hong and Brueggemann, 2000; Singh and Koh, 2009).

Young adults form a significant portion of backpack users and constitute a major proportion of the workforce and the student population (Abaraogu et al., 2016). Nevertheless, the recommendations of safe load are based on children of school age (Avantika, 2013; Walicka-Cupryś et al., 2015). Therefore, we expect that assessing the influence of carrying a backpack on young adults' variability of gait patterns may provide deeper understanding of how physical loads affect gait characteristics under routinely situations.

Gait variability performs an essential role in producing movement patterns that are adaptable and can be observed during transitions between different tasks; therefore, a gait variability increase is seen as either detrimental in some cases (end-point variability) or beneficial in others (coordinative variability) (Van Emmerik et al., 2016). Spatiotemporal parameters' variability relates to coordinative variability, whose increase implies a richer motor repertoire as an adaptive strategy to deal with perturbation during walking, as carrying a backpack load.

In this context, our hypothesis was that increasing load and different positions alters spatiotemporal parameters and their variability, leading to excessive activation of muscles, and increased gait instability. Therefore, the aim of this study was assess young adults' gait spatiotemporal parameters and their variability when carrying a backpack with different loads in various positions.

\section{Methods}

\section{Subjects}

Twenty-one healthy young subjects (10 male and 11 female, $23.7 \pm 5.3$ years old, $67.8 \pm 13.0 \mathrm{~kg}$ weight, and $1.69 \pm 0.08 \mathrm{~m}$ height) participated in the study. All participants were students of the University to whom was explained the aim of the study. They were healthy, without any musculoskeletal injury or pain at the time of data collection. Prior to participation, each subject voluntarily signed an informed consent form approved by the Institutional Ethics Committee for Human Research (1.003.935). The experiments involved a low risk given that constituted in just walking on a treadmill with a backpack, for a brief period, with loads commonly used, and under constant surveillance of the researchers. The results were posteriorly presented to the participants, as well as the recommendations reported here.

\section{Equipment and procedures}

For gait assessment, kinematic analysis was performed using a 3-D motion capture system comprising 10 infrared cameras operating at $100 \mathrm{samples} / \mathrm{s}$ (Vicon Nexus, Oxford Metrics, Oxford, UK). Seven reflective markers were attached to the lateral malleoli, heel, head of the second metatarsal (bilaterally), and the spinous process first thoracic vertebrae (T1).

The subjects walked on a level treadmill at their corresponding preferred walking speed (PWS), evaluated by a previously reported protocol (Kang and Dingwell, 2008), wearing their own regular shoes. The PWS was used in all trials. In addition, a curved-strap backpack was used, and its weight was matched to $10 \%$ and $20 \%$ of the BW for each subject. Each subject performed seven trials of 4 min apiece under the following conditions: 1) a control condition, without carrying a backpack (CC); 2) a backpack positioned bilaterally on the back containing $10 \%$ of each subject's BW (B10); 3) a backpack positioned bilaterally on the back containing $20 \%$ each subject's BW (B20); 4) a backpack positioned unilaterally on the back containing $10 \%$ of each subject's BW (U10); 5) a backpack positioned unilaterally on the back containing $20 \%$ of each subject's BW (U20); 6) a backpack positioned bilaterally on the front containing $10 \%$ of each subject's BW (F10); 7) a backpack positioned bilaterally on the front containing $20 \%$ of each subject's BW (F20) (Figure 1). The backpack was positioned at the lumbar level during back positions. The experimental conditions were randomly assigned to each subject, with a rest of 2 min between each trial.

\section{Data analysis}

Before data analysis, kinematic data were low-pass filtered using a fourth-order, zero-lag Butterworth filter with a cut-off frequency of $6 \mathrm{~Hz}$. Next, heel strikes and toe-offs were detected using the zero-cross of the heel markers velocity, determining all steps (Zeni et al., 2008). Then, the intermediate 150 strides were selected, which was the reasoning behind using the treadmill, discarding the initial and final strides. A customized MATLAB code was used for data analysis.

Step frequency (SF) was determined as the inverse of the average duration between two subsequent heel-strikes. 
The average step length (SL) was calculated as the ratio between the average treadmill speed and the average SF. Walk ratio (WR) was calculated as SL normalized by $\mathrm{SF}(\mathrm{WR}=\mathrm{SL} / \mathrm{SF})$ (Terrier and Reynard, 2015). Step width (SW) was determined as the medial-lateral (ML) distance between two subsequent heel-strikes.

Stance phase (StP) was calculated as the mean period between heel strike and toe off of the same foot. Swing phase (SwP) was calculated as the mean period since the ending of stance phase until the next heel strike of the same foot. Finally, double stance phase (DStP) was measured as the mean period between the heel strike of a foot and the next toe-off of the contralateral foot. All these parameters were normalized by the total gait cycle duration, and reported as a percentage.

Gait spatiotemporal parameters and their standard deviations (SD) for each trial were used to assess changes in gait pattern and variability: step frequency standard deviation (SFSD); step length standard deviation (SLSD); stride width standard deviation (SWSD); stance phase standard deviation (StPSD); swing phase standard deviation (SwPSD) and double stance phase standard deviation (DStPSD).

\section{Statistical analysis}

For comparison with $\mathrm{CC}$, we used a one-way repeated measures ANOVA design for the variables with a normal distribution (SL, SF, WR, SW, SWSD, SLSD; Shapiro-Wilk test, $p>0.05$ ), followed by Bonferroni post hoc tests. The remaining variables (StP, SwP, DStP, SFSD, StPSD, SwPSD, DStPSD) were tested using the nonparametric Friedman design test, followed by a post-hoc analysis using a Wilcoxon signed-rank test with a Bonferroni correction applied. To verify the interaction between the backpack load and position, we used a two-way repeated measures ANOVA design for the variables SL, SF, WR, and SW.

Statistical analysis was performed using SPSS software (version 23, SPSS Inc., Chicago, IL), with a significance level set at $p<0.05$.

\section{Results}

Table 1 summarizes gait spatiotemporal parameters under evaluated conditions. Our SL and SF findings show that frontal conditions differed from others as seen in B20, leading to alteration in WR for these conditions.

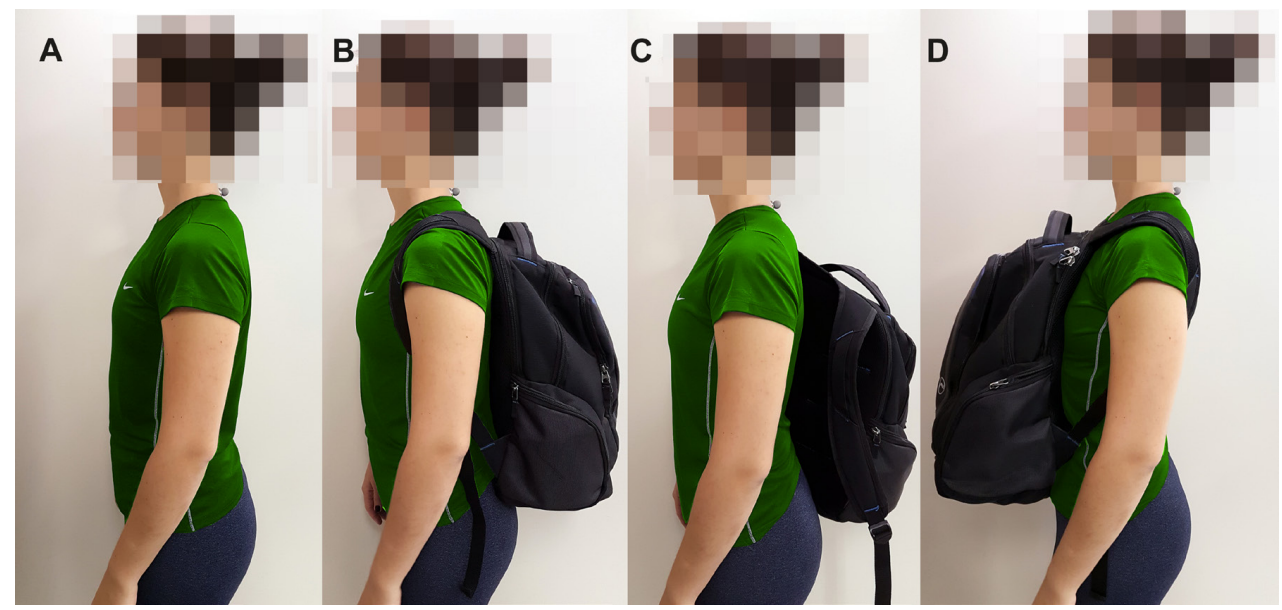

Figure 1. Backpack positioning: (A) without carrying a backpack; (B) backpack positioned bilaterally on the back; (C) backpack positioned unilaterally on the back; (D) backpack positioned bilaterally on the front.

Table 1. Spatiotemporal parameters under different backpack conditions.

\begin{tabular}{crrrrrrrr}
\hline Variables & \multicolumn{1}{c}{ CC } & B10 & B20 & U10 & U20 & F10 & F20 & $\boldsymbol{p}$ \\
\hline SF (step/s) & $1.78 \pm 0.12$ & $1.75 \pm 0.08$ & $1.75 \pm 0.13$ & $1.77 \pm 0.12$ & $1.78 \pm 0.13$ & $1.81 \pm 0.12$ & $1.85 \pm 0.12$ & $<0.001 *$ \\
SL (cm) & $62.68 \pm 5.95$ & $62.72 \pm 5.77$ & $63.74 \pm 5.43$ & $63.09 \pm 5.57$ & $62.68 \pm 5.39$ & $61.78 \pm 5.80$ & $60.65 \pm 5.89$ & $<0.001 *$ \\
SW (cm) & $7.47 \pm 4.17$ & $6.76 \pm 2.87$ & $7.41 \pm 3.04$ & $6.47 \pm 3.06$ & $7.24 \pm 3.16$ & $6.73 \pm 3.24$ & $7.07 \pm 3.30$ & $0.297 *$ \\
WR (cm·s/step) & $0.35 \pm 0.03$ & $0.35 \pm 0.03$ & $0.36 \pm 0.03$ & $0.35 \pm 0.03$ & $0.35 \pm 0.02$ & $0.34 \pm 0.03$ & $0.32 \pm 0.03$ & $<0.001 *$ \\
DStP (\%) & $10.62 \pm 1.91$ & $10.41 \pm 1.30$ & $11.18 \pm 2.08$ & $10.66 \pm 1.57$ & $10.47 \pm 1.26$ & $10.24 \pm 1.28$ & $10.62 \pm 1.51$ & $<0.001 * *$ \\
StP (\%) & $60.62 \pm 1.90$ & $60.40 \pm 1.30$ & $61.17 \pm 2.07$ & $60.66 \pm 1.57$ & $60.47 \pm 1.25$ & $60.23 \pm 1.28$ & $60.62 \pm 1.51$ & $<0.001 * *$ \\
SwP (\%) & $39.37 \pm 1.90$ & $39.59 \pm 1.30$ & $38.82 \pm 2.07$ & $39.33 \pm 1.57$ & $39.52 \pm 1.25$ & $39.76 \pm 1.28$ & $39.37 \pm 1.51$ & $<0.001 * *$ \\
\hline
\end{tabular}

Step frequency (SF); step length (SL); stride width (SW); walk ratio (WR); double stance phase (DStP); stance phase (StP); swing phase (SwP); control condition (CC); back with 10\% BW (B10); back with 20\% BW (B20); unilateral with 10\% BW (U10); unilateral with 20\% BW (U20); frontal with 10\% BW (F10); frontal with 20\% BW (F20). *repeated measure ANOVA. **Friedman test. 
Table 2. Gait variability under different backpack conditions.

\begin{tabular}{cllllllll}
\hline Variables & CC & B10 & B20 & U10 & U20 & F10 & F20 & $p$ \\
\hline SFSD (Hz) & 0.03 & 0.03 & 0.04 & 0.04 & 0.05 & 0.04 & 0.04 & $<0.001^{*}$ \\
SLSD (cm) & 1.47 & 1.51 & 1.76 & 1.57 & 1.91 & 1.47 & 1.48 & $<0.001$ \\
SWSD (cm) & 1.89 & 2.12 & 2.51 & 2.22 & 2.94 & 2.03 & 2.26 & $<0.001$ \\
DStPSD (\%) & 0.825 & 0.862 & 1.029 & 0.875 & 1.099 & 0.864 & 0.961 & $<0.001^{*}$ \\
StPSD (\%) & 1.209 & 1.249 & 1.487 & 1.293 & 1.689 & 1.213 & 1.336 & $<0.001^{*}$ \\
SwPSD (\%) & 0.761 & 0.785 & 0.883 & 0.820 & 0.996 & 0.777 & 0.887 & $<0.001^{*}$ \\
\hline
\end{tabular}

Step frequency standard deviation (SFSD); step length standard deviation (SLSD); stride width standard deviation (SWSD); walk ratio (WR); double stance phase standard deviation (DStPSD); stance phase standard deviation (StPSD); swing phase standard deviation (SwPSD); control condition (CC); back with $10 \% \mathrm{BW}$ (B10); back with $20 \% \mathrm{BW}$ (B20); unilateral with $10 \% \mathrm{BW}(\mathrm{U} 10)$; unilateral with $20 \% \mathrm{BW}$ (U20); frontal with $10 \% \mathrm{BW}$ (F10); frontal with $20 \%$ BW (F20). *Friedman test.

Table 3. Significant pairwise comparisons between conditions of the spatiotemporal variables. The numbers between parentheses refer to the pair of the conditions that presented significant difference: (1) CC; (2) B10; (3) B20; (4) U10; (5) U20; (6) F10; (7) F20.

\begin{tabular}{cc}
\hline Variables & Pairwise comparison \\
\hline SF (step/s) & $(1<6) ;(1<7) ;(3<5) ;(3<7) ;(4<6) ;(5<7) ;(6<7)$ \\
SL (cm) & $(1<3) ;(1>6) ;(1>7) ;(2<3) ;(2>6) ;(3<5) ;(3>7) ;(4>6) ;(5>7) ;(6>7)$ \\
SW (cm) & $(4<5)$ \\
WR (cm·s/step) & $(1<3) ;(1>6) ;(1>7) ;(2<3) ;(2>6) ;(3>5) ;(3>7) ;(4>6) ;(5>7) ;(6>7)$ \\
DStP (\%) & $(1<3) ;(1<4)$ \\
StP (\%) & $(1<3) ;(1<4)$ \\
SwP (\%) & $(1>3) ;(1>4)$ \\
SFSD (Hz) & $(1<3) ;(1<5) ;(2<3) ;(3<5)$ \\
SLSD (cm) & $(1<3) ;(1<5) ;(2<3) ;(4<5) ;(5>7)$ \\
SWSD (cm) & $(1<2) ;(1<3) ;(1<4) ;(1<5) ;(1<7) ;(2<3) ;(3<5) ;(3>7) ;(4<5) ;(5>7) ;(6<7)$ \\
DStPSD (\%) & $(1<3) ;(1<5) ;(1<7) ;(2<3) ;(4<5) ;(5>7)$ \\
StPSD (\%) & $(1<3) ;(1<5) ;(2<3) ;(3<5) ;(4<5) ;(5>7)$ \\
SwPSD (\%) & $(1<3) ;(1<5) ;(1<7) ;(6<7)$
\end{tabular}

Step frequency (SF); step length (SL); stride width (SW); walk ratio (WR); double stance phase (DStP); stance phase (StP); swing phase (SwP); step frequency standard deviation (SFSD); step length standard deviation (SLSD); stride width standard deviation (SWSD); double stance phase standard deviation (DStPSD); stance phase standard deviation (StPSD); swing phase standard deviation (SwPSD). (1) control condition (CC); (2) back with 10\% BW (B10); (3) back with $20 \% \mathrm{BW}(\mathrm{B} 20)$; (4) unilateral with 10\% BW (U10); (5) unilateral with 20\% BW (U20); (6) frontal with 10\% BW (F10); (7) frontal with $20 \% \mathrm{BW}$ (F20).

Gait cycle phases showed an increase in the B20 condition for DStP and StP, whereas SwP presented reduction in the $\mathrm{B} 20$ condition.

Table 2 demonstrates gait spatiotemporal parameters variability under evaluated conditions.

Pairwise comparison was applied to identify the influence of different loads for the same position (for instance, B10 to B20) and the influence of the same loads for different positions (for instance, B20 to U20), since results would be inconclusive for comparisons between different loads and different positions, viewed simultaneously (for instance, B10 to U20). The statistical significant differences are presented in the Table 3.

Figure 2 presents the interaction plots between the two factors: backpack load and position. There were significant main effects in position for SL $(p<0.001)$, SF $(p<0.001)$, and WR $(p<0.001)$. There was a significant interaction effect between load and position only for SL $(p<0.001)$. There was a significant main effect of load only for SW $(p=0.001)$.
The highest variability of spatiotemporal parameters and gait phases occurred in the U20 condition. In addition, all load conditions with $20 \% \mathrm{BW}$ showed a greater variability when compared to the $10 \% \mathrm{BW}$ counterpart (Figure 3).

\section{Discussion}

In the present study, gait spatiotemporal parameters and their variability in young adults when carrying a backpack with different loads and positions were assessed. The results demonstrated that spatiotemporal parameters, except for SW, and gait variability presented alterations with different loads and positions.

We used a constant treadmill speed across all conditions for the same subject, to isolate the effect of speed. In our results, SL increased when SF decreased, as expected when maintaining a constant speed, diverging of other studies that used different walking speeds among various study conditions (Attwells et al., 2006; Berceanu et al., 2016; Chow et al., 2005; Singh and Koh, 2009; Yoo, 

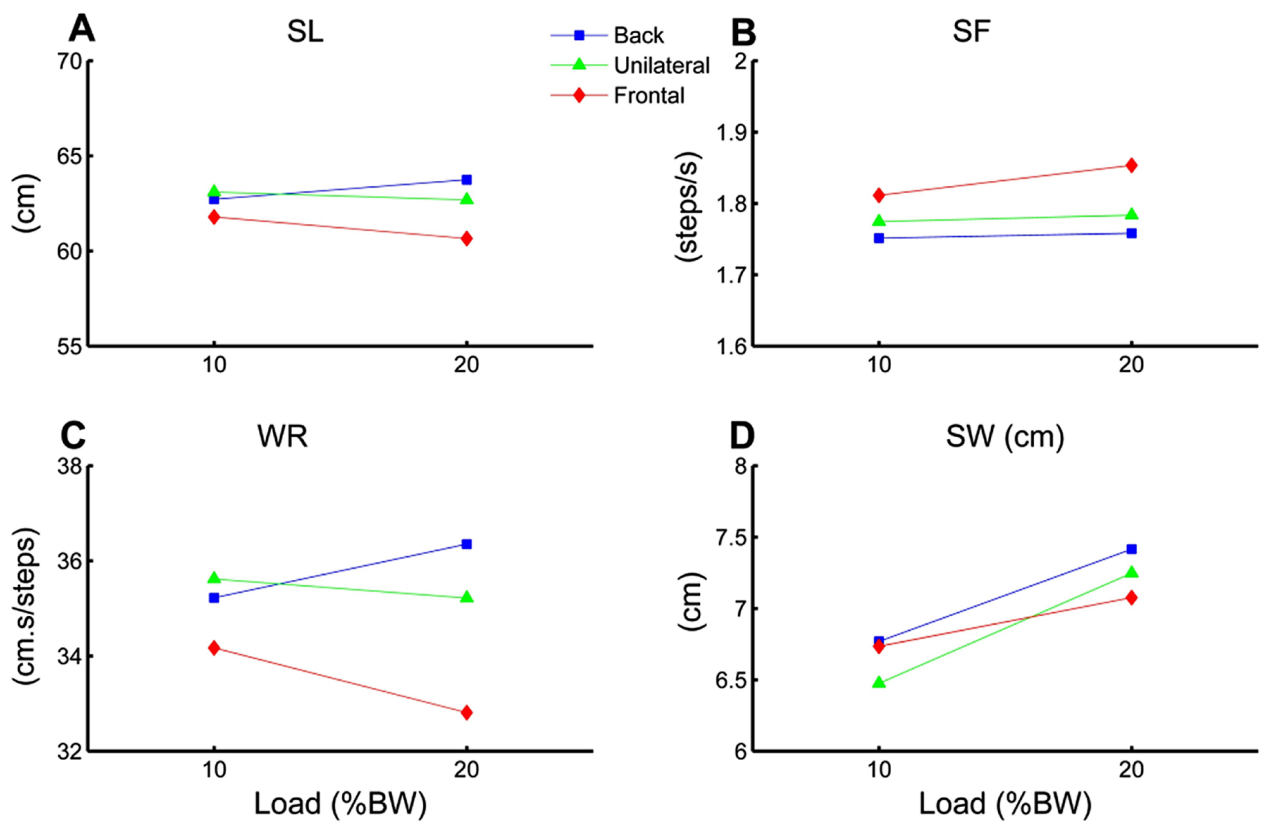

Figure 2. Load versus position interaction graph of spatiotemporal: (A) step length (SL); (B) step frequency (SF); (C) walk ratio (WR); and (D) step width (SW).
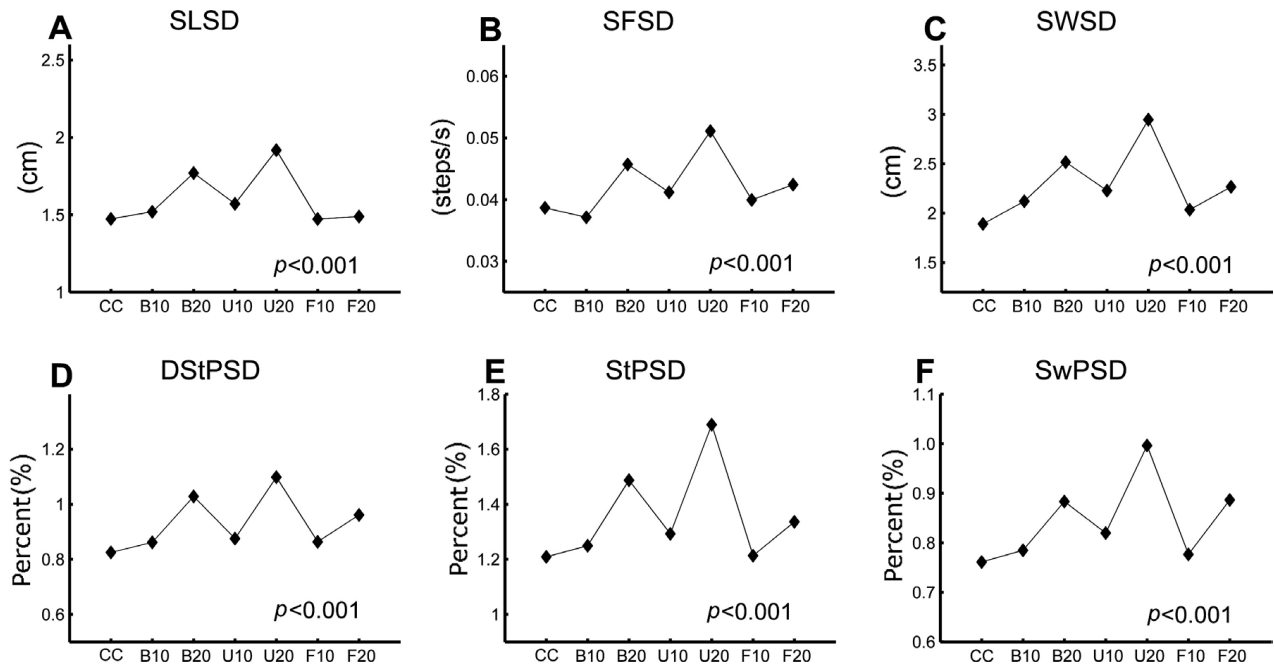

Figure 3. Behavior of gait cycle standard deviation among seven conditions. (A) step length standard deviation (SLSD); (B) step frequency standard deviation (SFSD); (C) stride width standard deviation (SWSD); (D) double stance phase standard deviation (DStPSD); (E) stance phase standard deviation (StPSD); (F) swing phase standard deviation (SwPSD). Control condition (CC); back with 10\% BW (B10); back with 20\% BW (B20); unilateral with $10 \% \mathrm{BW}(\mathrm{U} 10)$; unilateral with $20 \% \mathrm{BW}$ (U20); frontal with $10 \% \mathrm{BW}$ (F10); frontal with $20 \% \mathrm{BW}$ (F20).

2014) or with heavier load than $20 \% \mathrm{BW}$ and constant walking speed (Birrell and Haslam, 2009).

SL, SF and WR showed significant alterations both in our study findings and in other studies, suggesting that the body is being forced to adopt different strategies to reduce the mechanical stress on the musculoskeletal system when increasing the carried load (Attwells et al., 2006; Yoo, 2014), independent of speed. Although the subjects walked at their corresponding PWS under all backpack conditions, our results showed alterations in these parameters, especially in the $20 \%$ BW load (Tables 1 and 2).

Our results supported those of Abaraogu et al. (2016), whose methodology maintained a very similar walking speed among different conditions. They evaluated young adults on the treadmill in conditions with and without a backpack, with either one or two straps, and with a $15 \%$ BW load. Although their results were not 
significant, they found an increase in SL. We found the same result for backpacks containing a $10 \% \mathrm{BW}$ load; however, the increase in SL became significant for 20\% BW load conditions (Table 1). Conversely, Chow et al. (2005) assessed the influence of $15 \%$ BW loads in adolescents and found that SL decreased with the increased load and Birrell and Haslam (Birrell and Haslam, 2009) also found reduction in young adults using load ranging 8-32 kg. Together, these findings suggest that a $15 \% \mathrm{BW}$ load is detrimental to gait patterns for adolescents, while this threshold would be between $15-20 \%$ BW for young adults.

In addition, SL and SF (and thus, WR) were only affected in conditions when the backpack was bilaterally positioned in front or back, suggesting that these variables are insensitive to alterations in load position along a mediolateral direction. Similar results were found in a previous study in unilateral position (one strap) with 15\% BW load (Abaraogu et al., 2016). Furthermore, back bilateral positioning of the load increased SL and decreased SF, while frontal positioning produced opposite effects in these variables, as shown in Table 1. Finally, SL and SF were not significantly affected in the B10 position, whereas those variables were impacted in the B20, F10, and F20 conditions (Table 3). These results suggest that while $10 \% \mathrm{BW}$ is a safe load for a young adult to carry in the back, it might not be safe to carry it in a frontal position. Moreover, it might not be secure for a young adult to carry a $20 \% \mathrm{BW}$ load in either the frontal or back position.

SL showed significant main effect of load and significant interaction effects between load and position, suggesting that the effect of load was dependent upon the position (SL decreased with unilateral and frontal loads and increased in the back condition) (Figure 2A).

The practical meaning of these results further support that carrying $10 \% \mathrm{BW}$ seems to be a safe load in young adults, since the body can cope with the different backpack positions and maintain gait patterns. However, increasing this load to $20 \%$ BW degrades walking performance, and changing backpack positions affects gait significantly, showing that the subjects fail to maintain their gait pattern.

SF and WR showed significant main effects in certain positions (Figure 2B and C). SW presented significant main effect of load (Figure 2D), and pairwise comparison showed that this difference probably concerned only U10 versus U20 conditions (Table 3). Results from Yoo (2014) showed that there were no differences in SW when increasing loads, contrasting with our results in unilateral conditions.

SW was more affected by unbalanced loads in unilateral conditions, while SL, SF, and WR were more affected by unbalanced loads in both the bilateral back and front conditions (Table 3). These results indicate, therefore, that there could be a relationship between anteroposterior balance and SL, SF, and WR, while these variables do not suffer much influence of uneven lateral loads. Concurrently, SW demonstrated itself to be more susceptible to asymmetrical loads in the mediolateral direction were less influenced by uneven loads in the anteroposterior direction.

Kinoshita (1985) indicated that backpack position can induce a forward trunk tilt of about $6^{\circ}-11^{\circ}$. Thus, the observed gait alterations could also be a consequence of trunk leaning. Other studies reported that the vertical location of the load on the back provokes different amounts of forward trunk lean (Devroey et al., 2007; Knapik et al., 2004; Singh and Koh, 2009). In addition, the craniovertebral angle significantly decreased during load carrying, suggesting that the head acts to counterbalance a load (Attwells et al., 2006). Therefore, leaning strategies adopted by the motor system when carrying uneven loads and their influence on gait patterns should be a subject of further investigations. One study showed that increased trunk tilt raised lower limb muscular demand and energy absorption during walking, particularly during the stance phase (Kluger et al., 2014).

Singh and Koh (2009) found a significant increase in DStP for $20 \%$ BW in children when compared to an unloaded condition. Chow et al. (2005) showed that DStP increased and StP reduced significantly with increasing backpack loads from $7.5 \%-15 \%$ BW in adolescents, Wang et al. (2001) also observed the same result in college students with progressive loads starting from $15 \% \mathrm{BW}$, such as other studies found increase of DStP in young adults with increasing load (Birrell and Haslam, 2009; Kinoshita, 1985). We observed a significant increase in DStP only under the B20 and U10 conditions (Table 1), supporting the findings of the aforementioned studies using two straps in the back loaded position. As expected, SwP revealed opposite behavior of StP, decreasing significantly in B20 and U10 conditions (Table 1). These results indicate that gait changes may have occurred to minimize gait destabilization caused by backpack load and position (Singh and Koh, 2009).

In this way, previous studies have associated double stance time as a measure of control and stability during walking given by a larger base of support for a greater period of time that can reduce trips and falls (Birrell and Haslam, 2009; Hong and Brueggemann, 2000; McGraw et al., 2000). The increase of double stance minimizes the demands on the musculoskeletal system because when both the feet are in contact with the ground, the mechanical demand on the whole system would be lesser compared to when only one foot remains in contact with the ground (Majumdar et al., 2010; Singh and Koh, 2009). Furthermore, similar to SL, SF, and WR, 
the duration of gait cycle phases could be strongly correlated with forward or backward trunk leaning, since such gait phases showed themselves to be affected by uneven loads along with anteroposterior direction, while being remarkably affected by unbalanced loads in the back position (Table 3).

In the F10 and F20 conditions, the three temporal parameters showed the same behavior as in the $\mathrm{B} 10$ and $\mathrm{B} 20$ conditions, but on a smaller scale with no significant changes, where DStP reduced under $10 \% \mathrm{BW}$ loads and increased in 20\% BW loads (Table 3 ) and StP, with an opposite result for SwP (Table 1). This finding is notable, considering that only B20 was significantly different when compared to CC (Table 3), showing greater values for DStP and StP and reduction for SwP (Table 2). Furthermore, it is possible that increasing loads greater than $20 \% \mathrm{BW}$, when carried in the front, may significantly alter gait cycle phases. Our findings showed that gait cycle phases are primarily affected by loads carried on the back, but could also be affected by heavier loads in the frontal position.

Though of a small magnitude, increased load (20\% BW) induced a correspondingly significant increase in variability of spatiotemporal parameters (Table 2 and Figure 3). Increased variability, within certain limits, may be interpreted as variations in an increased motor repertoire, probably used to minimize gait destabilization and to maintain balance (Singh and Koh, 2009). Furthermore, 20\% BW backpack weight causes the most significant muscular and postural changes in any conditions (Al-Khabbaz et al., 2008), so it should be avoided.

Fellin et al. (2016) found increased DStP and DStPSD with incremental loads from $20 \mathrm{~kg}$ to $40 \mathrm{~kg}$ using a backpack in soldiers. In a broad sense, we can observe the same characteristic in our study, where the greater variability was found with higher loads (Table 3 ).

In summary, SF, SL and WR were altered by both bilateral frontal and back positions, while SW changed by the unilateral position under increased load. The DStP and StP showed greater variability with unilateral and bilateral back positions and SwP for frontal position with higher loads.

Our hypothesis was supported: where increasing loads and different positions altered gait spatiotemporal parameters and their variability. These findings can aid better understanding of gait characteristics. In summary, unbalanced loads in anteroposterior positions influenced SL, SF, WR, DStP, and StP, while unbalanced loads in mediolateral positions affected SW and SwP. In a broad sense, variability increased across all spatiotemporal variables for all tested conditions.

Finally, 20\% BW loads should be avoided in any position (unilateral, bilateral back, and frontal), since it significantly alters gait parameters, particularly gait variability. These recommendations may assure increased gait stability, decreased trunk forward lean and, hence, decreased muscle activation and fatigue reducing back pain occurrence. However, in the frontal position not even a $10 \%$ BW load was proven to be a safe limit, showing a strong influence on gait spatiotemporal parameters.

\section{Acknowledgements}

The authors are grateful to government agencies CAPES, CNPq, FAPEG and FAPEMIG.

\section{References}

Abaraogu UO, Ugwa WO, Onwuka E, Orji E. Effect of single and double backpack strap loading on gait and perceived exertion of young adults. Journal of Back and Musculoskeletal Rehabilitation. 2016; 29(1):109-15. PMid:26406186. http:// dx.doi.org/10.3233/BMR-150605.

Al-Khabbaz YSSM, Shimada T, Hasegawa M. The effect of backpack heaviness on trunk-lower extremity muscle activities and trunk posture. Gait \& Posture. 2008; 28(2):297-302. PMid:18329270. http://dx.doi.org/10.1016/j.gaitpost.2008.01.002.

Attwells RL, Birrell SA, Hooper RH, Mansfield NJ. Influence of carrying heavy loads on soldiers' posture, movements and gait. Ergonomics. 2006; 49(14):1527-37. PMid:17050392. http://dx.doi.org/10.1080/00140130600757237.

Avantika R, Agarwal S, Bharti S. Postural effect of back packs on school children: its consequences on their body posture. International Journal of Health Sciences and Research. 2013; 3:109-16.

Berceanu C, Marghitu DB, Gudavalli MR, Raju PK, Vikas Y. Gait analysis parameters of healthy human subjects with asymmetric loads. Computer Methods in Biomechanics and Biomedical Engineering. 2016; 19(8):855-63. PMid:26274771. http://dx.doi.org/10.1080/10255842.2015.1075008.

Birrell SA, Haslam RA. The effect of military load carriage on 3-D lower limb kinematics and spatiotemporal parameters. Ergonomics. 2009; 52(10):1298-304. PMid:19787507. http:// dx.doi.org/10.1080/00140130903003115.

Brackley HM, Stevenson JM, Selinger JC. Effect of backpack load placement on posture and spinal curvature in prepubescent children. Work. 2009; 32(3):351-60. PMid:19369727.

Chow DHK, Kwok MLY, Au-Yang ACK, Holmes AD, Cheng JCY, Yao FYD, Wong MS. The effect of backpack load on the gait of normal adolescent girls. Ergonomics. 2005; 48(6):642-56. PMid:16087499. http://dx.doi.org/10.1080/00140130500070921.

Dames KD, Smith JD. Effects of load carriage and footwear on spatiotemporal parameters, kinematics, and metabolic cost of walking. Gait \& Posture. 2015; 42(2):122-6. PMid:25985924. http://dx.doi.org/10.1016/j.gaitpost.2015.04.017.

Devroey C, Jonkers I, Becker A, Lenaerts G, Spaepen A. Evaluation of the effect of backpack load and position during standing and walking using biomechanical, physiological and subjective measures. Ergonomics. 2007; 50(5):728-42. PMid:17454090. http://dx.doi.org/10.1080/00140130701194850. 
Fellin RE, Seay JF, Gregorczyk KN, Hasselquist L. Spatiotemporal parameters are not substantially influenced by load carriage or inclination during treadmill and overground walking. Journal of Human Kinetics. 2016; 50(1):27-35. https://doi.org/10.1515/ hukin-2015-0138.

Hebenstreit F, Leibold A, Krinner S, Welsch G, Lochmann M, Eskofier BM. Effect of walking speed on gait sub phase durations. Human Movement Science. 2015; 43:118-24. PMid:26256534. http://dx.doi.org/10.1016/j.humov.2015.07.009.

Heuscher Z, Gilkey DP, Peel JL, Kennedy CA. The association of self-reported backpack use and backpack weight with low back pain among college students. Journal of Manipulative and Physiological Therapeutics. 2010; 33(6):432-7. PMid:20732580. http://dx.doi.org/10.1016/j.jmpt.2010.06.003.

Hong Y, Brueggemann GP. Changes in gait patterns in 10-yearold boys with increasing loads when walking on a treadmill. Gait \& Posture. 2000; 11(3):254-9. PMid:10802438. http:// dx.doi.org/10.1016/S0966-6362(00)00055-2.

Hong Y, Li JX, Fong DTP. Effect of prolonged walking with backpack loads on trunk muscle activity and fatigue in children. Journal of Electromyography and Kinesiology. 2008; 18(6):990-6. PMid:17720538. http://dx.doi.org/10.1016/j. jelekin.2007.06.013.

Kang HG, Dingwell JB. Separating the effects of age and walking speed on gait variability. Gait \& Posture. 2008; 27(4):572-7. PMid:17768055. http://dx.doi.org/10.1016/j. gaitpost.2007.07.009.

Kinoshita H. Effects of different loads and carrying systems on selected biomechanical parameters describing walking gait. Ergonomics. 1985; 28(9):1347-62. PMid:4065090. http:// dx.doi.org/10.1080/00140138508963251.

Kluger D, Major MJ, Fatone S, Gard SA. The effect of trunk flexion on lower-limb kinetics of able-bodied gait. Human Movement Science. 2014; 33:395-403. PMid:24423389. http:// dx.doi.org/10.1016/j.humov.2013.12.006.

Knapik JJ, Reynolds KL, Harman E. Soldier load carriage: historical, physiological, biomechanical, and medical aspects. Military Medicine. 2004; 169(1):45-56. PMid:14964502. http:// dx.doi.org/10.7205/MILMED.169.1.45.

LaFiandra M, Wagenaar RC, Holt KG, Obusek JP. How do load carriage and walking speed influence trunk coordination and stride parameters? Journal of Biomechanics. 2003; 36(1):87-95. PMid:12485642. http://dx.doi.org/10.1016/ S0021-9290(02)00243-9.

Majumdar D, Pal MS, Majumdar D. Effects of military load carriage on kinematics of gait. Ergonomics. 2010; 53(6):782-91. PMid:20496244. http://dx.doi.org/10.1080/00140131003672015.
McGraw B, McClenaghan BA, Williams HG, Dickerson J, Ward DS. Gait and postural stability in obese and nonobese prepubertal boys. Archives of Physical Medicine and Rehabilitation. 2000; 81(4):484-9. PMid:10768540. http:// dx.doi.org/10.1053/mr.2000.3782.

Pau M, Corona F, Leban B, Pau M. Effects of backpack carriage on foot-ground relationship in children during upright stance. Gait \& Posture. 2011; 33(2):195-9. PMid:21112213. http:// dx.doi.org/10.1016/j.gaitpost.2010.10.096.

Qu X, Yeo JC. Effects of load carriage and fatigue on gait characteristics. Journal of Biomechanics. 2011; 44(7):1259-63. PMid:21397234. http://dx.doi.org/10.1016/j.jbiomech.2011.02.016.

Sheir-Neiss GI, Kruse RW, Rahman T, Jacobson LP, Pelli JA. The association of backpack use and back pain in adolescents. Spine. 2003; 28(9):922-30. PMid:12942009. http://dx.doi. org/10.1097/01.BRS.0000058725.18067.F7.

Singh T, Koh M. Effects of backpack load position on spatiotemporal parameters and trunk forward lean. Gait \& Posture. 2009; 29(1):49-53. PMid:18667319. http://dx.doi. org/10.1016/j.gaitpost.2008.06.006.

Springer S, Gottlieb U, Lozin M. Spatiotemporal gait parameters as predictors of lower-limb overuse injuries in military training. The Scientific World Journal. 2016; 2016(2016):5939164. PMid:27478864. http://dx.doi.org/10.1155/2016/5939164.

Terrier P, Reynard F. Effect of age on the variability and stability of gait: a cross-sectional treadmill study in healthy individuals between 20 and 69 years of age. Gait \& Posture. 2015; 41(1):170-4. PMid:25455699. http://dx.doi.org/10.1016/j. gaitpost.2014.09.024.

Van Emmerik REA, Ducharme SW, Amado AC, Hamill J. Comparing dynamical systems concepts and techniques for biomechanical analysis. Journal of Sport and Health Science 2016; 5(1): 1-11. https://doi.org/10.1016/j.jshs.2016.01.013

Walicka-Cupryś K, Skalska-Izdebska R, Rachwał M, Truszczyńska A. Influence of the weight of a school backpack on spinal curvature in the sagittal plane of seven-year-old children. BioMed Research International. 2015; 2015:817913. PMid:26413545. http://dx.doi.org/10.1155/2015/817913.

Wang Y, Pascoe DD, Weimar W. Evaluation of book backpack load during walking. Ergonomics. 2001; 44(9):858-69. PMid:11560366. http://dx.doi.org/10.1080/00140130118572.

Yoo B. The effect of carrying a military backpack on a transverse slope and sand surface on lower limb during gait [dissertation]. Salt Lake City, UT, USA: The University of Utah; 2014.

Zeni JA Jr, Richards JG, Higginson JS. Two simple methods for determining gait events during treadmill and overground walking using kinematic data. Gait \& Posture. 2008; 27(4):710-4. PMid:17723303. http://dx.doi.org/10.1016/j.gaitpost.2007.07.007. 